\title{
BASIS PROPERTIES OF $p$-EXPONENTIAL FUNCTION OF LINDQVIST AND PEETRE TYPE
}

\section{ÖZlem Bakşi, Petr Gurka, Jan Lang And Osvaldo Méndez}

Abstract. We show that a $p$-exponential function defined by the $p$-trigonometric functions of Lindqvist and Peetre form a basis in the Lebesgue space $L^{r}\left((-1,1)^{n}\right)$ for any $r \in(1, \infty)$, provided $n \leqslant 3$ and $p>p_{n} \geqslant 1$.

Mathematics subject classification (2010): 46B15, 42B05, 42A32, 33B10, 33E30.

Keywords and phrases: Generalized trigonometric functions, generalized exponential functions of Lindqvist and Peetre type, generalized Fourier series.

\section{REFERENCES}

[1] O. BAKŞI, P. GURKA, J. LANG, AND O. MÉNDEZ, Basis properties of Lindqvist-Peetre functions in $L^{r}(0,1)^{n}$, Rev. Mat. Complut. 30 (1): 1-12, 2017.

[2] P. Binding, L. Boulton, J. ČEPIČKa, P. DRÁBeK, AND P. GIRG, Basis properties of eigenfunctions of the p-Laplacian, Proc. Amer. Math. Soc. 134 (12): 3487-3494 (electronic), 2006.

[3] L. Boulton And G. Lord, Approximation properties of the q-sine bases, Proc. R. Soc. Lond. Ser. A Math. Phys. Eng. Sci. 467 (2133): 2690-2711, 2011.

[4] L. Boulton And H. Melkonian, Generalised cosine functions, basis and regularity properties, Unpublished manuscript, 2016.

[5] P. J. Bushell AND D. E. EdmUnds, Remarks on generalized trigonometric functions, Rocky Mountain J. Math. 42 (1): 25-57, 2012.

[6] A. P. Buslaev AND V. M. TiKhomirov, The spectra of nonlinear differential equations and widths of Sobolev classes, Mat. Sb. 181 (12): 1587-1606, 1990.

[7] A. P. Buslaev AND V. M. Tikhomirov, Spectral theory of nonlinear equations and $n$-widths of Sobolev spaces, In Methods of approximation theory in complex analysis and mathematical physics (Leningrad, 1991), vol. 1550 of Lecture Notes in Math., pages 19-30, Springer, Berlin, 1993.

[8] P. DRÁBEK AND R. MANÁSEVICH, On the closed solution to some nonhomogeneous eigenvalue problems with p-Laplacian, Differential Integral Equations 12 (6): 773-788, 1999.

[9] D. E. Edmunds, P. Gurka, And J. LAnG, Properties of generalized trigonometric functions, J. Approx. Theory 164 (1): 47-56, 2012.

[10] R. E. EdwARDS, Fourier series, vol. 2, vol. 85 of Graduate Texts in Mathematics, Springer-Verlag, New York-Berlin, second edition, 1982, A modern introduction.

[11] Á. ElBert, A half-linear second order differential equation, In Qualitative theory of differential equations, vol. I, II (Szeged, 1979), vol. 30 of Colloq. Math. Soc. János Bolyai, pages 153-180. NorthHolland, Amsterdam-New York, 1981.

[12] J. LANG AND D. E. EDMUNDS, Eigenvalues, embeddings and generalised trigonometric functions, volume 2016 of Lecture Notes in Mathematics, Springer, Heidelberg, 2011.

[13] V. LeVIn, Notes on inequalities, II. On a class of integral inequalities, Rec. Math. Moscou, n. Ser. 4: 309-324, 1938.

[14] P. LindQvist, On the equation $\operatorname{div}\left(|\nabla u|^{p-2} \nabla u\right)+\lambda|u|^{p-2} u=0$, Proc. Amer. Math. Soc. 109 (1): 157-164, 1990.

[15] P. LindQVist, Some remarkable sine and cosine functions, Ricerche Mat. 44 (2): 269-290 (1996), 1995. 
[16] P. Lindqvist And J. Peetre, $p$-arclength of the q-circle, Math. Student 72 (1-4): 139-145 (2005), 2003.

[17] P. Lindquist And J. Peetre, Comments on Erik Lundberg's 1879 thesis, especially on the work of Göran Dillner and his inuence on Lundberg, Mem. dell'Istituto Lombardo, Accad. Sci. e Lett., Classe Sci. Mat. Nat. XXXI, Fasc. 1. Milano, 2004.

[18] M. ÔTANI, A remark on certain nonlinear elliptic equations, Proc. Fac. Sci. Tokai Univ. 19: 23-28, 1984.

[19] J. PeEtre, The differential equation $y^{\prime p}-y^{p}= \pm 1 \quad(p>0)$, Ricerche Mat. 43 (1): 91-128, 1994.

[20] A. PINKUS, $n$-widths of Sobolev spaces in $L^{p}$, Constr. Approx. 1 (1): 15-62, 1985.

[21] E. SCHMIDT, Über die Ungleichung, welche die Integrale über eine Potenz einer Funktion und über eine andere Potenz ihrer Ableitung verbindet, Math. Ann. 117: 301-326, 1940.

[22] F. WeIsZ, Summability of multi-dimensional trigonometric Fourier series, Surv. Approx. Theory 7: $1-179,2012$. 